39. Codium adhærens, Ag.

Jap. Hai-miru.

Hab. Ins. Ishikaki (H.K.).

40. Halimeda Opuntia, Lamour.

Jap. Saboten-gusa (Okam.).

Hab. Ins. Ishikaki (H. K.).

41. Halimeda Tuna, Lamour.

Jap. Uchiwa-saboten (H. K. nom. nov.).

Hab. Ins. Okinawa: Tomari (H. K.).

42. Halimeda tridens, Lamour.

Jap. Mitsude-saboten (H. K. nom. nov.).

Hab. Ins. Okinawa: 'T'omari (H. K.).

\title{
List of Plants collected in Mt. Hakusan and its vicinities.
}

By

Tsutsumi Ichimura.

\section{（加州白山及其附近探集植物目錄）}

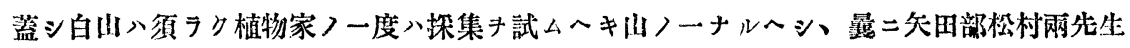

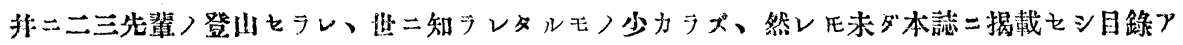
キ聞カズ、因テ金澤附近二於テ余り見ザル類ノミ擇羅シ、以テ大方識者〉溯正キ乞ハントス、植

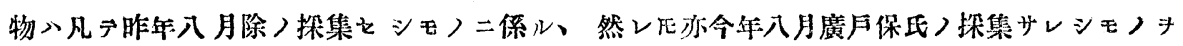

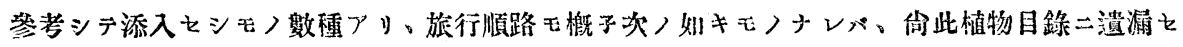

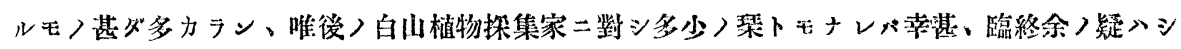

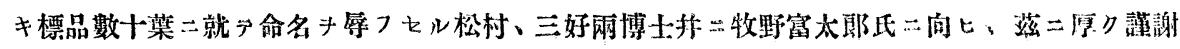
フ意キ表ス。 


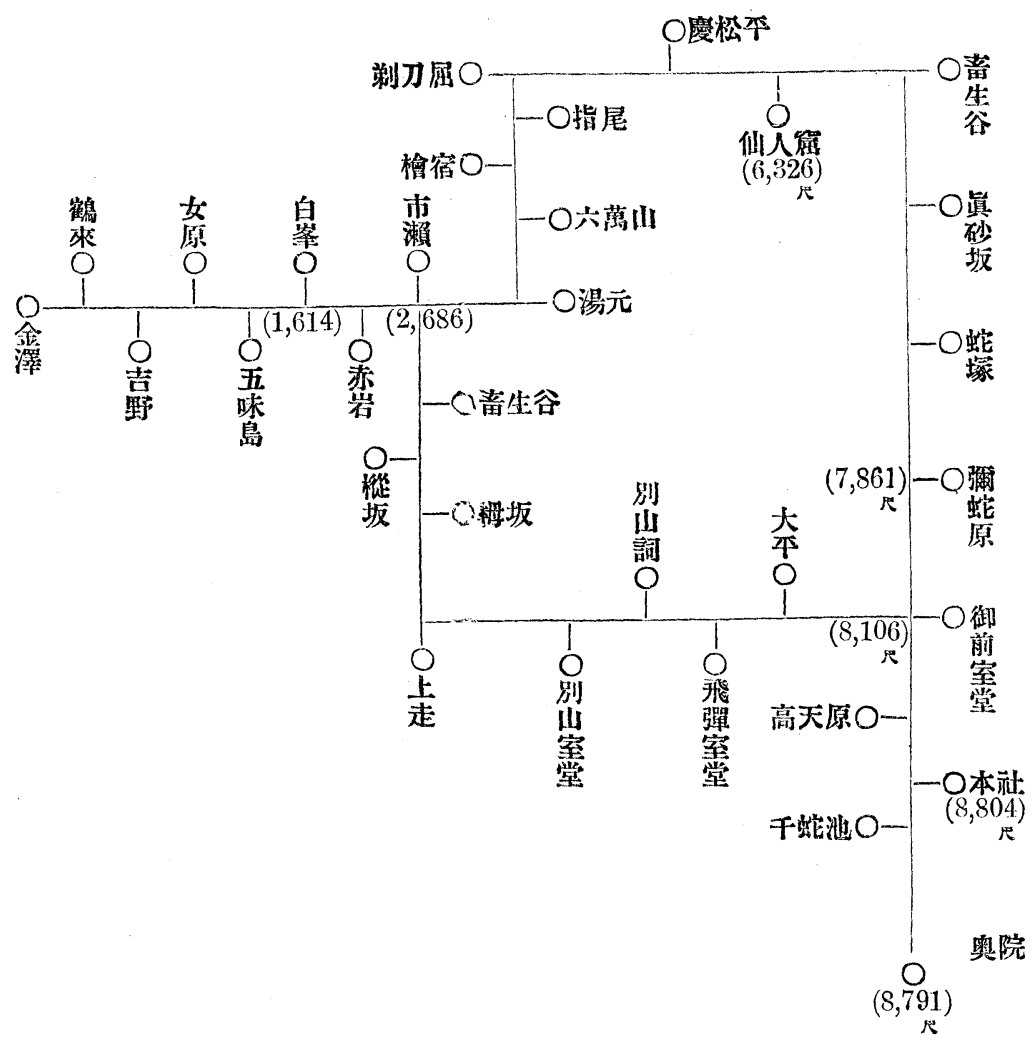

In the following list medicinal plants are noted with asterisk.

\section{Lichenes.}

* Cetraria islandica, var. angustifolia, Krysoth. 依蘭苔 (飛彈室堂) Cladonia coccifera, (Ls) Schaer. ハナ゙゚ケ (上走) Persusaria leptanata, (Müll) Ar $\%$.

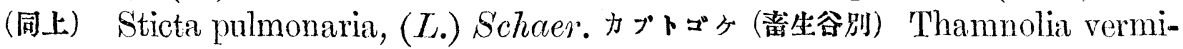

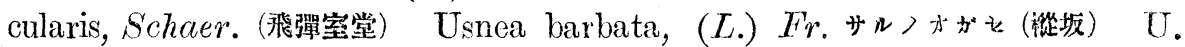
longissima, Ach. (同上)

\section{Filicinae.}

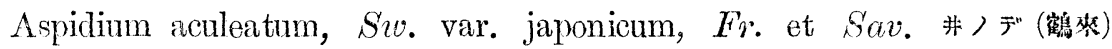
A. decursive-pinnatum, Kze. ゲシゲシシダ (女原) A. sophoroides Sw.ホシダ

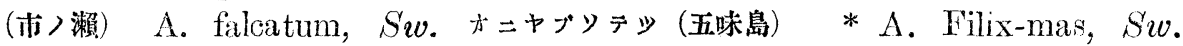
キシダ (市)瀨) A. glanduligerum, Kue. ハシゴシが(女原) A. muticum,

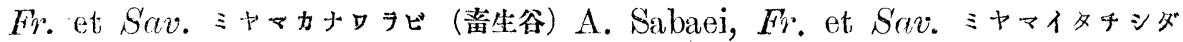
(同上) A. viridescens, Miq. リヤシメンシダ.(市瀨) Asplenium japonicum,

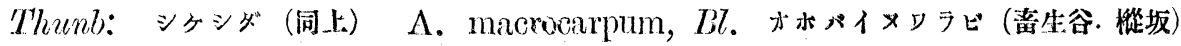


Asplenium mesosorum Mak メリサラビ (菻生谷) Botrychium virginianum, Sw.ナッノハナロラビ(同上) Lomaria alnata, $13 l$. キジカシダ(同上) Lomaria Matsumureana, Malino. ヤマソテッ (畫生谷) Lygodium japonicum, Sw.ツルシフブ(鶴雨) Onoclea orientalis, Hook.イヌガングク (白紧) Polypodium phegopteris $L$. ミヤママラビ (甫瀨) P. ensatum, Thunb.クリハラン(女原) P.

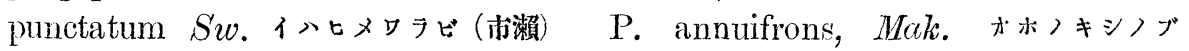

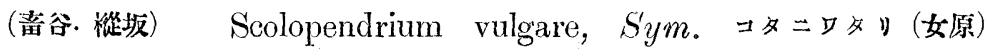

\section{Lycopodinae.}

Lycopopium obscurum, L. マンチンスギ(梅岥) * I. clavatum, L. ヒカゲ ノカッ゙ラ (吉野一) L. serratum, Thunnb、タシグシバ(同上) Selaginella invol-

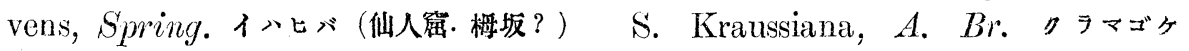
吉野一)

\section{Coniferinae.}

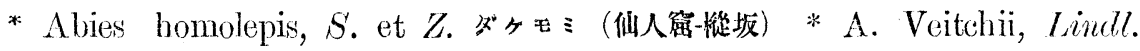

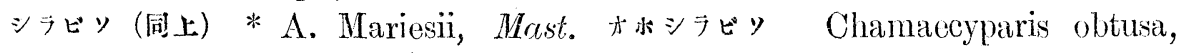
$S$. et $Z$. 七ノ (燴宿) * Larix Jeptolepis, Gord. フシマッ (上走) Pinus pumila, Pall。ハ七マע (御前㗌堂) Sciadupytis verticillata, S. et Z. (中宮)

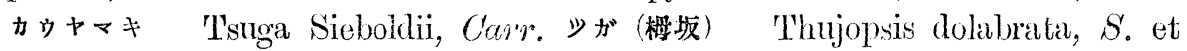
ク. ヒバ (榆復)

\section{Monocotyledonae.}

\section{Graminae.}

Agrostis perennans, Tuck. 又力ボ (赤岩) Bambusa Veitchii, Car\%. クマサ・(同上) Brachypodium Japonicum, Miq. カモ沙クサ (市瀨) B. silvaticum, $R$. et $S$. ヤマカ琣少少（湯元） Calamagrostis Halleriana, $D C$.

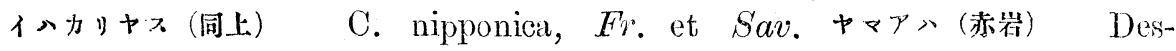
champsia flexuosa, Tyin コメス、 (白紧) Dactylis glomerata, L. カれがヤ

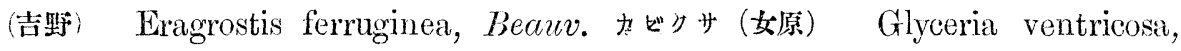
Hack. ドダヤウリナギ(吉野) Meliea nutans, L。 コメがヤ（五味島）Molinia japonica, Hack。 ヌマガヤ(闹上) Poa sphondylodes, Trin.イチゴッナキ(鶴米) P. sudetica, Hcenke. ミヤマイチロ゙リナキ(吉野) Spodiopogon sibiricus, Trin. カホフブタス、キ(五味島)

\section{Cyperaceae.}

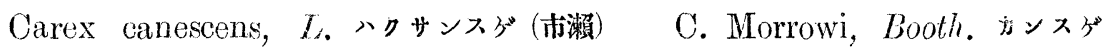
(鶴來一) C. amphora, Fr. et Sav. ミヤマカンスゲ(白鋕) C. plocamugyne, Mtax. エタメキタン (同上) C. tenuissima, Booth. イトスゲ (五味島) C. Thunbergii, Steud. アがスダ（吉野） Fimbristylis japonica, Sieb et Zucc.ヤマ* (五味島) Scirpus eriophorum, Michx. var. nipponicus, Fr. et Sav. アブフがヤ (书) 瀨) * Sparganium longifolium, T'urc\%。ミシリ（鶴來一) 


\section{Araceae.}

* Arisaema japonicum, Bl. テンナンシャウ(市ノ瀨) Lysichiton cantschatense, Schott. ミッ゙バシャウ(甶生谷洌) *Pinellia tuberifera, I'en.カラスビ シャク(棫濑. 白峰)

\section{Juncaceae.}

Juncus prismatocarpus, $R$. Br. var. Leschenaultii $F$. Buch. カサがセ キシャサ（五㞲島）J. xiphoides, E. Mey. ミクリカウがイセキシャウ（同上） Luzula campestris var. capitata, Miy. スぶメノヒx(鶴來)

\section{Liliaceae.}

Clintonia udensis, Trautv. ツバメカモ卜 (音生谷) Fritillaria camtschateusis, Gand. クロエy(铜蛇原. 御前室堂) Heloniopsis breviscapa, Max. シャウジサッがマ(吉野一) Lilium avenaceum, Fisch.クルマンリ（女原. 上走）

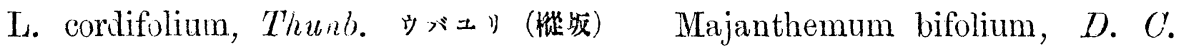
マヒッ゙ルサウ(畜生谷別) Metanarthecium foliatum, Max. 子バリノ゙ギタン(赤岩) Narthecium asiaticum, Max. キンコウクロ (畜生谷別) Paris tetraphylla, $A$. Gr. ックバ子サウ(大飛平彈室堂） P. japonicum， Fr. キメがササウ（大平）

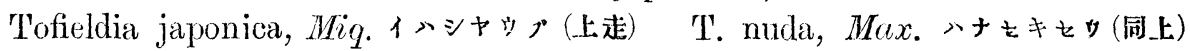
Trillium Smallii, Max. xンレイサウ(大平) Tricyrtis macropoda, Mi .

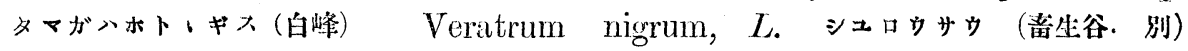
V. stamineum, Max. コペイタイ(闰上) V. Maximowiczii，Bak.アカヤギサウ (從坂) V. album, L. var grandiflorum, Max. バイタイサウ（音生谷） Smilax herbacea, $L$. var. nipponica, Max. シォデ (壱野) Streptopus amplexifolius, $D C$. オ水バタタシマラン(童生谷) S. ajanensis, Tiling var. japonica, Max. ダタシラン (同上)

\section{Dioscoriaceae.}

Dioscoria Tokwo, Makino. アマドコロ (白笔) D. quinqueloba, Thunb. キクバドコロ (女原)

\section{Iridaceae.}

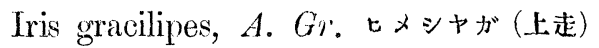

\section{Orchideae.}

Ephippianthus Schmidtii, Richib.f. エイチェフラレ(囷生谷別) Gymnadenia conopea, R. Br. テカタチドリ (㔊山窒堂) Orchis aristata, Fisch.ハクサンチドリ

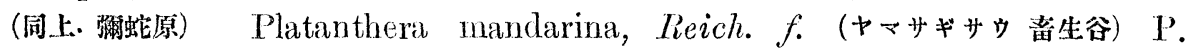
sacharinensis, $F$. Schm. ヤホホマサギササ(同上) Spiranthes australis, Lincll. 子シバナ(鶴來)

\section{Dicotyledonae.}

\section{Chloranthaceae.}

Chloranthus serratus, $R$. et $S$. フヌシシッ゙カ(童生谷，檜宿） 


\section{Betulaceae.}

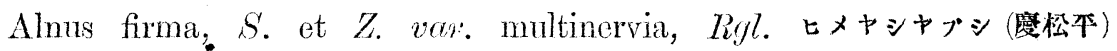

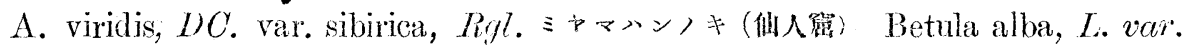
vulgaris, $D C$. ミラカンが(愉俩) B. Ermanni, Cham. var. nipponica, Max. タタカンバ (同上) Carpinus japonica, $B l$.クマシデ（仙人笜）

Fagaceae.

Fagus japonica, Max.イメブナ（销管・素生谷） F. sylvatica， L. var. Sieboldi, Max。ブナ゙キ(同上) Quercus dentata, Thunb. カシメ(指尾) Q. serrata, Thunb. ク×キ(布瀨)

\section{Salicaceae.}

Salix Sieboldiana, $B l$. イハャナキ (上走) Populus balsamifera, $C$. var Suaveolens, Lond。デロ (仙人窟)

\section{Morae.}

Broussonetia Kasinoki, Sieb. カッ゙（市頪)

\section{Urticaceae.}

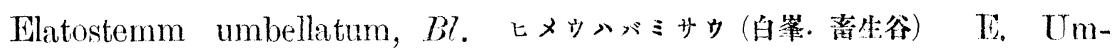
bellatum, $B$ l. var. majus, Max. サハバミサシ (白峰)

\section{Aristolochiaceae.}

Asarum variegatum, A. Bl. イサハカンアフヒ（女原）

\section{Polygonaceae.}

*Polygonum Bistortal, L. イブキトラフカ (上走) P. tenuicanle, Bisset. et Moor. ヒイイブキトラフか（同上） P. polymorphum, Ledeb. var. japonicum, Max. トンタデ (異砂咙) *P. cuspidatum, S. et K. イタドリ (吉野) P. senticosum, Meisn.マリノシリメグヒ(鶴來)

\section{Caryophyllaceae.}

Dianthus barbatum, var. shinanensis, Yatclbe. ミヤマナデシコ(上走) * D. superbus, $L$. カハシナデショ (女㷧. 吉野. 御花息) Stellaria florida, Fisch. var. angustifolia, Max. イハッメクサ（林社. 奥院)

\section{Magnoliaceae.}

Magnolia hypoleuer, S. et $Z . \quad$ 木つフキ(白鉴)

\section{Ranunculaceae.}

* Aconitum Fischeri, Reich ヤマトリカブト(嗇生谷) Actaea spicata, L.

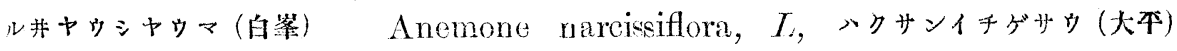
A. altaica，Fisch。キクサギイチリンサッ（毒生谷） A. flaccida Fr. Schm.

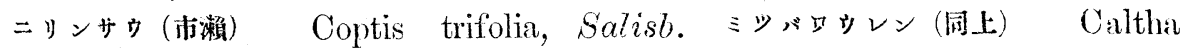
palustris, L. var. sibirica, Rgl。 エンカカリウ(别山室堂) Coptis trifolia. Salish.

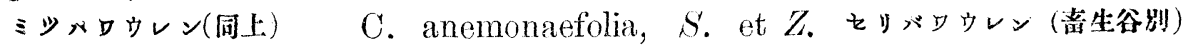
Clematis heracleifolia, DC. var. stans, O.K.クサホダン (吉野) C. alpina, Mill. 


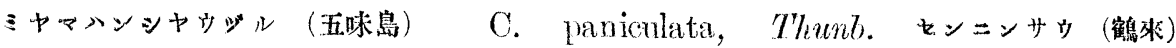
Ranunculus acris, $L$. Steveni, $R g l$. ミヤマキンポヴ゙。(大本) Thalictrum

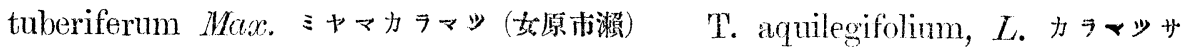

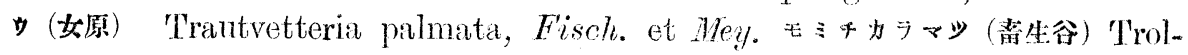
lins putulus, Salisb.シナノキンボイザ（大本）

\section{Lardizabalaceae.}

*Akebia lobata, Done.ミミッ゙アルビ(㭉瀨)

\section{Berberideae,}

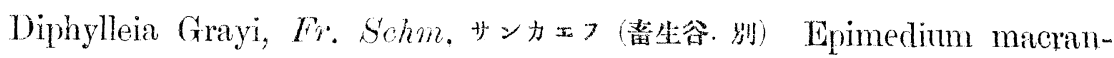
thum. Moor. et Dcne。イカリサッ(鶴來)

\section{Papaveraceae.}

* Chelidonium majus, L. クタノサウ(鶴來) Corydalis decumbens, Pers. ヤブメンゴサク (同上) C. pallida, Pers. var. キかマン(同上)

\section{Cruciferae.}

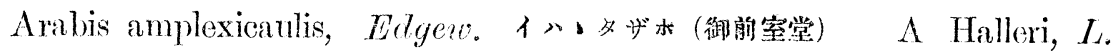
ハクサンハタザホ(同上) A. perfoliata, Lam.ハタザホ(吉野) Barbarea vulgaris，

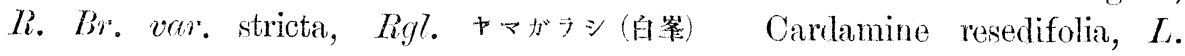
ミヤマタ子ッタバナ(御前室堂)

\section{Droseraceae.}

Drosera rotundifolia， I. モシャンゴゲ (市瀨)

\section{Crassulaceae.}

Sedum japonicum, Sieb。ツンングサ (吉野) S. kamtschaticum, Fisch. キリンサウ (赤岩)

\section{Lauraceae.}

Lindera umbellata, Thunb. 口ロモ滔生谷)

\section{Saxifragaceae.}

Astilbe chineusis, Max. var. japonica, Max. チダダサシ(吉野) A. japonica, Miq. みロャリサッ(女原) シ Astilbe Thunbergii, Miq. トリアシシャ シマ(吉野) Cardiandra alternifolia，S. et Z。クサアヂサ非 (女原) Hydrangea scandens, Max. ジタッッ゙ル(赤岩) H. hirta， S. et Z. ヤマアダサ\#（五味島） H. Hortensis, Sm. var. acuminata, A. Gray. がクバナ (女原) H. involucrata,

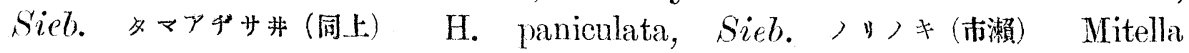
japonica, Miq. チャルメルサウ(同上) Parnassia palustris，L。ウメバチササ (者生谷. 别) Philadelphus, coronarius， $L$. バイクロシッギ (赤岩) Rodgersia

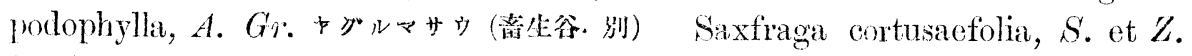
(同上) S. fusca, Max. ワロクもサウ(同上) Tiarellia polyphylla, Don。ッダヤ ダイモンヂサックシン（闹上）

(To be continued.) 